\title{
Seguridad y Soberanía alimentaria en el marco de los Objetivos de Desarrollo Sostenible, el papel de las fuerzas militares ${ }^{1}$
}

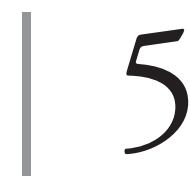

https://doi.org/10.21830/9789585318342.05

\author{
John Cristhian Fernández Lizarazo ${ }^{2}$ \\ Escuela de Aviación del Ejército \\ Leidy Johana Cabrera Cabrera ${ }^{3}$ \\ Escuela de Aviación del Ejército \\ Ricardo Alexander Peña Venegas ${ }^{4}$ \\ Universidad de la Salle
}

\section{Resumen}

La soberanía alimentaria puede ser definida brevemente como el derecho de los pueblos a elegir lo que comen y de qué manera quieren producir sus alimentos. La diferencia entre este término y la seguridad alimentaria es determinante para Colombia, en razón de su diversidad territorial. Al margen de los cuestionamientos políticos, la soberanía alimentaria se ejerce con más fuerza en las comunidades más alejadas de los centros urbanos y ha sido centro de atención con motivo de la pandemia originada por la enfermedad COVID-19 por infección del SARS-CoV-2. Precisamente, en los lugares recónditos del suelo colombiano, la presencia del Estado se evidencia de primera mano gracias a las Fuerzas Militares (en adelante FF. MM.). Por lo anterior, en este capítulo se conceptualizará el vínculo potencial entre las capacidades de las FF. MM. y la seguridad y soberanía alimentarias, con un énfasis especial en la pospandemia.

1 Este capítulo hace parte de los resultados del proyecto de investigación "Acciones estratégicas del Ejército Nacional orientadas al desarrollo sostenible en Colombia. Experiencia y reflexión desde la minería y los objetivos de desarrollo sostenible”, del Grupo de Investigación en Aviación Militar de la Escuela de Aviación del Ejército, registrado con el código COL0077618 y categorizado en C por Minciencias. Los puntos de vista y los resultados de este capítulo pertenecen al autor y no reflejan necesariamente los de las instituciones participantes.

$2 \mathrm{PhD}$ en Ciencias Agropecuarias y magíster en Ciencias Agrarias (Universidad Nacional de Colombia. Licenciado en Biología (Universidad Francisco José de Caldas). Director del Programa de Ingeniería Agronómica de la Universidad de La Salle. Orcid: https://orcid.org/0000-0001-9015-7404 - Contacto johfernandez@lasalle.edu.co

3 Magíster y especialista en Docencia e Investigación Universitaria (Universidad Sergio Arboleda). Trabajadora social (Universidad de La Salle). Docente e investigadora del Grupo de investigación en aviación militar. Orcid http://orcid.org/0000-0002-6398-6933 - Contacto: leidycabreracabrera@cedoc.edu.co

4 Doctor en Ciencias de la Vida (Universidad de Lausana, Suiza). MSc en Ciencias Agrarias (Universidad Nacional de Colombia). Ingeniero Agrónomo (Universidad Pedagógica y Tecnológica de Colombia). Consultor e investigador. https://orcid.org/0000-0002-4204-9043. 
Cabe anotar que tanto el Estado colombiano como la sociedad civil están comprometidos con el cumplimiento de los Objetivos de Desarrollo Sostenible (en adelante ODS), acuerdos universales que orientan las acciones de todos los gobiernos con fundamento en la sostenibilidad del planeta. Por tal motivo, las FF. MM. no son ajenas a este compromiso, lo que hace necesario analizar las implicaciones de los ODS en las acciones de aquellas. Finalmente, y frente a los escenarios mencionados, se plantea resolver una pregunta emergente referida al papel de las FF. MM. frente a la relación entre la soberanía alimentaria y los ODS.

Palabras clave: alimentación, cambio climático, militar, sostenibilidad, pandemia, SARS-CoV-2.

\section{Introducción}

Los términos seguridad y soberanía alimentarias involucran una serie de conceptos, normalmente confusos y algunas veces distorsionados, que distraen la atención sobre los verdaderos problemas que pretenden solucionar, en especial, de los racionales que sustentan su intencionalidad. Así, es importante desmitificar, a través de la aclaración contextual y conceptual, lo que implican estos dos conceptos, que se constituyen como eje de atención en medio de las coyunturas actuales desde los ámbitos ecológico, económico, ambiental y sanitario. Los ODS son la hoja de ruta de los países para afrontar el desarrollo sin agotar los recursos naturales. Con esta breve revisión no se pretende asumir una posición de favorabilidad o antítesis, sino ambientar, en su justa medida, el conocimiento en torno a la seguridad y soberanía alimentaria, a la luz de los ODS y las capacidades de las FF. MM. para garantizarlas. Para ello, este documento pretende aclarar los conceptos y luego relacionarlos en busca de fortalezas y oportunidades de acción institucional, para el abordaje de los retos globales referidos a alimentación humana.

\section{Marco teórico}

\section{Seguridad y soberanía alimentaria}

El térmico 'seguridad alimentaria' ha evolucionado paulatinamente desde la década de los setenta. En esa época, el concepto se basó solamente en la producción y disponibilidad de alimentos en cada país y en el mundo en general, luego, en la década de los ochenta, se integraron los componentes económico y físico como factores determinantes del acceso a los alimentos y, finalmente, en la década de los noventa se adicionaron la inocuidad y las preferencias culturales como elementos esenciales del concepto, por cuanto determinan la individualidad y particularidad 
de cada pueblo, convirtiendo así a la seguridad alimentaria en un derecho humano (Proyecto Food Facility Honduras, 2011).

La seguridad alimentaria tiene, en consecuencia, varios componentes que se deben cumplir en su totalidad para garantizar una seguridad alimentaria verdadera, estos son: la disponibilidad, la estabilidad, el acceso y la utilización biológica (Proyecto Food Facility Honduras, 2011).

La disponibilidad es un componente asociado a las características de producción locales y nacionales, que toma en cuenta no solamente los alimentos que se producen en el país, sino que también considera el producto de las importaciones, lo almacenado, las ayudas alimentarias, las pérdidas en postcosecha y las exportaciones.

La estabilidad implica un importante proceso de planeación local, ya que la producción de alimentos es, normalmente, cíclica. Así, en los países que tienen estaciones la producción de los alimentos se limita debido a la temperatura; por su parte, en los países del trópico, la producción de alimento normalmente se restringe debido a factores como el brillo solar, precipitaciones y temperatura, además de factores bióticos como las enfermedades y las plagas, que siempre están presentes en los cultivos durante su ciclo de producción. En este sentido, la estabilidad implica la capacidad de generar estrategias para garantizar el acceso a los alimentos en todo momento y de forma independiente de la estacionalidad de las cosechas.

El acceso y control sobre la producción se encuentran relacionados con la posibilidad de supervisar aquellos medios que la permiten, es decir: el agua, las tierras, los fertilizantes, el conocimiento, la tecnología, entre otros factores. De igual forma, implican la posibilidad de acceder a los alimentos del mercado, ya sea por cercanía geográfica o por capacidad de pago por los mismos.

El consumo y la utilización biológica hacen referencia a la consideración de aspectos locales de cada comunidad. Cada cultura puede tener costumbres alimentarias particulares que determinan la cantidad y tipo de alimento que consumen y que se produce en la región. De recibir un tipo de alimento que no es consumido por una comunidad particular, se pone en peligro la seguridad alimentaria y, por esta vía, la cultura misma; es por ello que este componente dignifica a las comunidades desde la equidad.

De igual forma, la inocuidad y el manejo general de los alimentos determinan su disponibilidad nutricional y sanitaria. Si un alimento está en malas condiciones nutricionales su absorción por parte del cuerpo no se da. Si un alimento está en malas condiciones sanitarias atenta contra la salud de las personas, en especial de las poblaciones vulnerables y de los niños; estos últimos conforman la franja pobla- 
cional a la que debe prestarse mayor atención a este respecto, por las consecuencias a largo plazo que una mala nutrición puede implicar.

El concepto de seguridad alimentaria se ha ido ajustado con el tiempo, como señala la Organización de las Naciones Unidas de la Alimentación y la Agricultura:

Existe seguridad alimentaria cuando todas las personas tienen, en todo momento, acceso físico y económico a suficientes alimentos, inocuos y nutritivos para satisfacer sus necesidades alimenticias y sus preferencias en cuanto a los alimentos, a fin de llevar una vida activa y sana. (FAO, 2006).

Definición que le otorga una mayor fuerza a la índole multidimensional de la seguridad alimentaria, a lo que habría que sumar "la disponibilidad de alimentos, el acceso a los alimentos, la utilización biológica de los alimentos y la estabilidad [de los otros tres elementos a lo largo del tiempo]" (FAO, 2006).

Para transitar desde el concepto de seguridad alimentaria hasta el de soberanía alimentaria, es importante aclarar la diferencia entre el derecho a estar protegidos contra el hambre y el derecho a tener una alimentación adecuada.

El primero corresponde al mismo derecho a la vida, por cuando señala la obligatoriedad de los Estados a garantizar que sus ciudadanos no mueran de hambre; el segundo derecho, en cambio, corresponde a la forma en que llegan los alimentos, pues deben llegar en la cantidad suficiente, en buen estado (calidad) y en todo momento, de tal forma que se pueda llevar una vida saludable y activa (Proyecto Food Facility Honduras, 2011).

Así, los Estados tienen una obligación clara con sus ciudadanos que, en sí misma, implica una adaptación de los mecanismos y criterios por los cuales se garantiza la seguridad alimentaria. La razón de esto radica en que cada pueblo es diferente debido a su historia y sus costumbres, por ello, la soberanía alimentaria ha sido definida como

el derecho de los pueblos, las naciones o las uniones de países a definir sus políticas agrícolas y de alimentos, sin ningún dumping frente a países terceros. La soberanía alimentaria organiza la producción y el consumo de alimentos acorde con las necesidades de las comunidades locales, otorgando prioridad a la producción para el consumo local y doméstico. Proporciona el derecho a los pueblos a elegir lo que comen y de qué manera quieren producirlo. La soberanía alimentaria incluye el derecho a proteger y regular la producción nacional agropecuaria y a proteger el mercado doméstico del dumping de excedentes agrícolas y de las importaciones a

5 El dumping se produce cuando una empresa exporta a precios inferiores a los que vende en su propio mercado (Guzmán-Barrón, 1997). 
bajo precio de otros países. Reconoce así mismo los derechos de las mujeres campesinas. La gente sin tierra, el campesinado y la pequeńa agricultura deben tener acceso a la tierra, el agua, las semillas y los recursos productivos, así como a un adecuado suministro de servicios públicos. La soberanía alimentaria y la sostenibilidad deben constituirse como prioritarias a las políticas de comercio. (European Coordination Via Campesina, 2018)

En este sentido, la soberanía alimentaria es un concepto determinante para la comprensión mutidimensional de la seguridad alimentaria. Dentro de las dimensiones que permiten abordar el concepto de soberanía alimentaria se incluyen los regímenes alimenticios locales, los derechos civiles y de ciudadanía, y otros que por su naturaleza misma orientan hacia un paradigma alternativo, es decir, hacia nuevas formas de comercio, prácticas agroecológicas, relaciones de género y equidad (Wittman, 2011. Por tal motivo, se considera que la agricultura alternativa y la soberanía alimentaria están estrechamente vinculadas y entre ellas debe existir un equilibrio.

Así, la soberanía alimentaria pretende acortar la distancia entre los consumidores y los productores, tanto así que existiría la posibilidad de eliminar la agricultura de la Organización Mundial del Comercio (WTO), por cuanto se restauraría el control sobre los recursos y mercados locales por parte de los pequeńos productores y se estimularía también a las cooperativas locales y la agricultura basada en la comunidad (CSA) (Macartan, 2017).

Se ha considerado que la orientación alternativa de la soberanía alimentaria contrasta con el modelo alimentario neoliberal. Por ejemplo, la seguridad alimentaria es vista, desde el modelo neoliberal, como un tema de producción intensiva basada en el principio de ventaja comparativa y de distribución a través de los diferentes mecanismos del mercado, en tanto que desde el modelo de soberanía alimentaria, la seguridad alimentaria de aborda a partir de la priorización de la producción agrícola local y de la protección de mercados locales (Wittman, 2011). De hecho, se ha propuesto que la soberanía alimentaria es, en sí misma, una alternativa crítica a la seguridad alimentaria, por cuanto su actual implementación es mayoritariamente desde el modelo neoliberal (Macartan, 2017).

En consideración de lo anterior, pareciera ser que la agricultura alternativa tuviera un vínculo mayor con la soberanía alimentaria, en contraste, la seguridad alimentaria pareciera estar más vinculada con el modelo neoliberal. No obstante, los límites entre estos conceptos no son fáciles de establecer, así que el mejor acercamiento posible consiste en comprender dos temas transversales aún no mencionados. Estos se fundamentan en datos cuantitativos y, por lo tanto, suponen 
elementos objetivos de realidad que enriquecen la discusión. Se trata de la alimentación mundial y el cambio climático en el contexto de la agricultura. La concepción de criterios en torno a la soberanía alimentaria, la seguridad alimentaria y la agricultura alternativa no sería posible sin conocer el contexto que se plantea a continuación.

\section{La seguridad alimentaria, el gran reto}

En cifras del Banco Mundial, en 1961 el suelo disponible para la agricultura era de 0,371 ha por persona, en tanto que en 2015, se redujo a 0,194 ha por persona (The World Bank, 2015). Por su parte, el incremento de la población mundial es acelerado, a pesar de la disminución de la fertilidad promedio. En la década de los setenta la tasa de fertilidad era mayor (4,5 nińos por mujer) que la actual (2,5 niños por mujer), lo que no es suficiente para disminuir la preocupación por las expectativas según las cuales, para el año 2050, la población mundial podría ser de aproximadamente 9500 millones de personas (United Nations Population Fund, 2018). Así las cosas, el preocupante incremento de la población mundial sumado a una reducción del suelo arable, en un $48 \%$ en poco más de medio siglo, ha puesto de manifiesto la preocupación por la seguridad alimentaria a nivel global, pero en especial en países con menor desarrollo.

Actualmente, la producción agrícola global es teóricamente suficiente para abastecer la demanda mundial, aun cuando la posibilidad de suministrar la demanda de alimentos no sea la misma en todos los países (Padmavathy \& Poyyamoli, 2011). Sorprendentemente, en países como Colombia, así como muchos otros del trópico, en donde la producción de alimentos es potencialmente posible durante todo el año, debido a la ausencia de estaciones, se importa entre el 20 y el 50\% de los alimentos (FAO, 2017) (ver figura 1).

Las razones para tal desfase radican en problemas multidimensionales de carácter local y global asociados con la pobreza, la inequidad y la desnutrición (FAO, 2017), que, en últimas, inducen a la aceleración global de la explotación agrícola e implican un incremento en la productividad (estimada en alrededor del 21\%); además, implican un aumento en la expansión del suelo arable a expensas de la disminución de los servicios ecosistémicos (Padmavathy \& Poyyamoli, 2011) (Figura 2). 


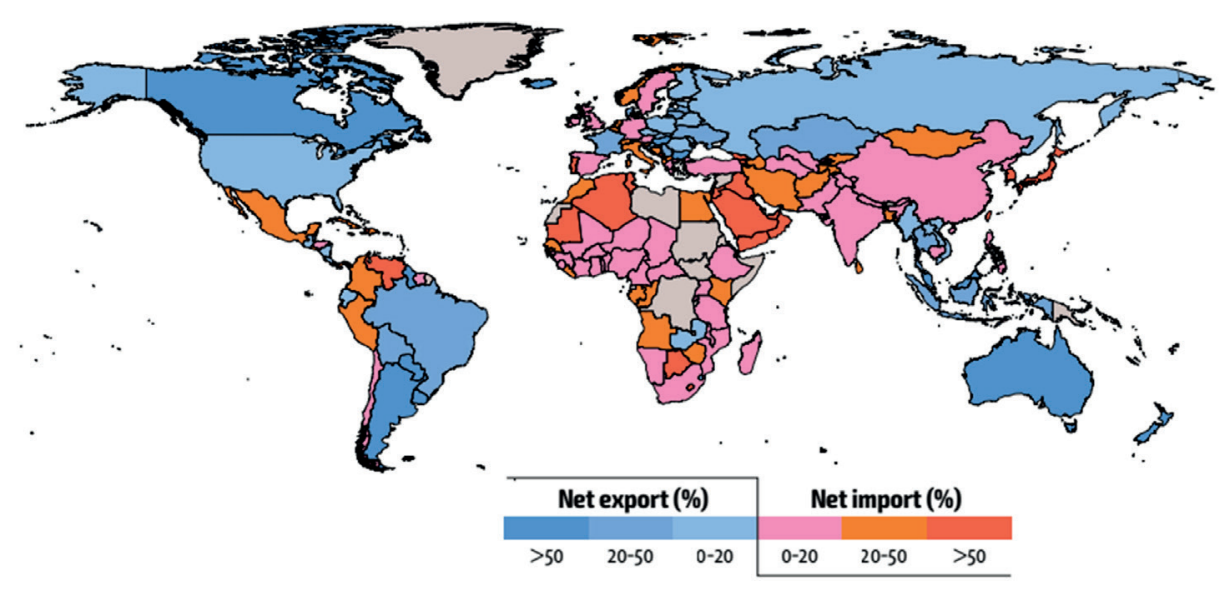

Figura 1. Porcentaje de importaciones netas de alimentos Fuente: FAO (2017)

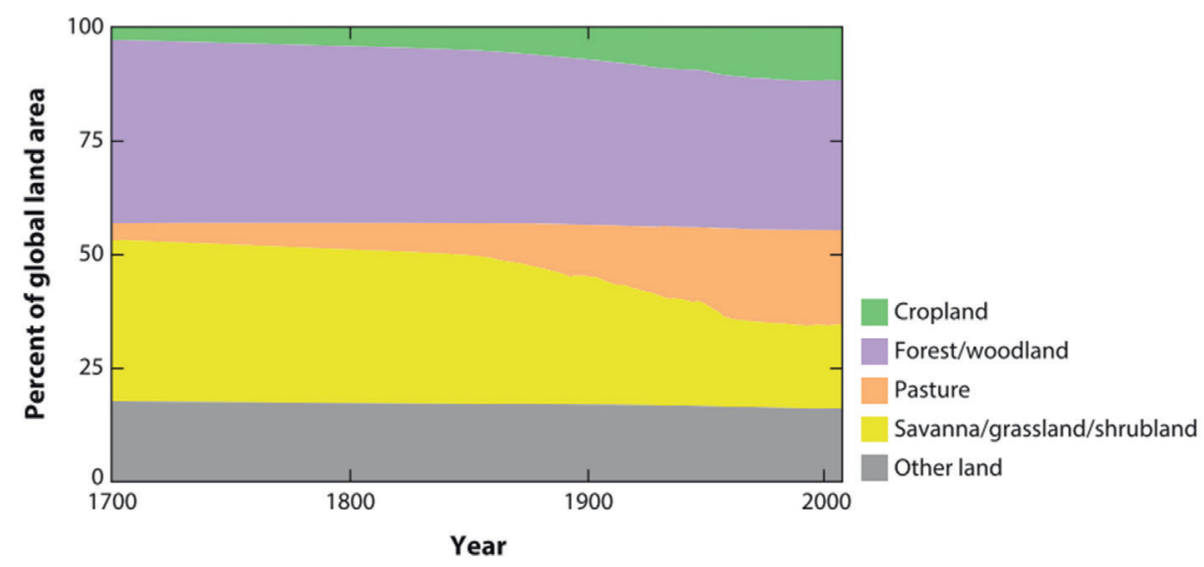

Figura 2. Tendencias globales en el uso del suelo desde 1700 hasta 2017 Fuente: Ramankutty et al. (2018)

La creciente demanda de alimentos aumenta la presión sobre los recursos naturales, lo que sumado a la disminución de los rendimientos de algunos cultivos en regiones afectadas por degradación de suelos y al alto precio de los agroquímicos (insecticidas, fungicidas y herbicidas) y fertilizantes, así como sus efectos sobre el medioambiente y la salud, hacen insostenible la producción de alimentos de manera tradicional. Este hecho ha generado la necesidad de buscar nuevas soluciones y alternativas, que apuntan a una agricultura más sostenible y sustentable para garantizar la seguridad alimentaria (Padmavathy \& Poyyamoli, 2011). 
Promover la agricultura familiar como herramienta de innovación socioproductiva y las prácticas de cultivo amigables con el medioambiente en sistemas tradicionales se plantea como una necesidad, donde el pequeño productor sea el principal proveedor de alimentos para consumo local y el mercado interno (FAO, 2016). De esta manera, se podría contribuir de manera significativa a un desarrollo rural más equitativo y a la disminución de la pobreza.

\section{El cambio climático cambió la agricultura}

La obligación de producir alimentos ha inducido una serie de problemas asociados con la preocupación de la no sostenibilidad de los sistemas agrícolas convencionales, particularmente en países en vías de desarrollo (Padmavathy $\&$ Poyyamoli, 2011). Por ejemplo, entre 2000 y 2010, aproximadamente el 80\% de la deforestación fue resultado de la conversión de suelos para pastos y agricultura (Kissinger et al., 2012); también se ha reportado que la agricultura aporta en el 92\% de la huella hídrica humana (Hoekstra \& Mekonnen, 2012); finalmente, considerando los biomas y grupos taxonómicos, la conversión a pastos y a cultivos ha resultado en pérdidas que se ubican entre un 20 y un $30 \%$ de la riqueza de especies locales (Newbold et al., 2015).

Una de las principales preocupaciones radica en que, junto con la deforestación y el cambio en el uso del suelo, la agricultura ha contribuido a la emisión de gases efecto invernadero en un 22\% (Smith et al., 2014), de hecho, Koerber y Kretschmer, citados en Padmavathy y Poyyamoli (2011), advirtieron que el 74\% de las emisiones provenientes de las actividades agrícolas se originan en países en desarrollo. Así, la mayoría del potencial de mitigación desde la agricultura se podría lograr a través del secuestro de carbono (89\%), y aproximadamente el $70 \%$ se podría realizar en países en desarrollo (Fischer et al., 2007).

Los modelos de predicción indican que la temperatura global se incrementará entre $1,8^{\circ} \mathrm{C}$ y $4^{\circ} \mathrm{C}$ al final del siglo XXI (IPCC, 2013), lo que estará acompanado de alteraciones aleatorias de tipo espaciotemporal, por ejemplo, en patrones de precipitación (Padmavathy \& Poyyamoli, 2011), lo que para los mismos autores implicará que algunos cultivos estarán beneficiados en algunas regiones del mundo, no obstante, se espera que los impactos generales del cambio climático sobre la agricultura sean negativos, amenazando la seguridad alimentaria global, en especial para la población de los países en desarrollo, que es la más vulnerable frente a la inseguridad alimentaria y que, probablemente, será la más seriamente afectada.

Gornall y otros (2010) clasificaron los impactos del cambio climático para la productividad agrícola global, esta clasificación incluye impactos directos, impactos 
indirectos, e impactos no climáticos pero relacionados en la composición atmosférica. Dentro de los impactos directos del cambio climático están: 1) los cambios del clima promedio, que afectan los rangos de vida asociados al crecimiento y desarrollo de las plantas; 2) la variabilidad climática, que dificulta la capacidad de predicción aumentando el riesgo de pérdidas de los cultivos; 3) las temperaturas extremas, que afectan la productividad primaria neta de los cultivos a partir de la producción de biomasa y las dificultades reproductivas de las plantas; 4) las sequías, que limitan el crecimiento y desarrollo de las plantas, por cuanto el agua es el factor más limitante en estos procesos; 5) las lluvias fuertes y las inundaciones, que generan estreses por anoxia a los cultivos, limitando la disponibilidad de oxígeno y sus procesos metabólicos; 6) las tormentas tropicales, que afectan de forma mecánica la totalidad de los sistemas agrícolas (Gornall et al., 2010).

Dentro de los impactos indirectos del cambio climático están: 1) las plagas y enfermedades de los cultivos, cuyos detonantes dependen de la disponibilidad de agua o de las condiciones apropiadas de temperatura para proliferar — por cuenta de la variabilidad climática se hace impredecible su incidencia-; y 2) cambios en la disponibilidad del agua debido a cambios en el clima de lugares remotos, por cuenta de la dependencia del agua utilizada en lugares que están distantes a donde esta es colectada (Gornall et al., 2010).

Los impactos no climáticos pero relacionados en la composición atmosférica incluyen: 1) la fertilización con dióxido de carbono presente en la atmósfera, que inicialmente puede ser positivo, pero dadas las interacciones con el agua y la temperatura, termina no siéndolo; y 2) el aumento del ozono en la atmósfera, que se constituye como un gas biocida y, por tanto, como un agente estresante que limita la productividad agrícola (Gornall et al., 2010).

El cambio climático es, en consecuencia, una amenaza para los sistemas de vida rurales, por ende, para la seguridad alimentaria. Esta situación pone en riesgo los avances logrados en la reducción del hambre y la pobreza en el mundo, en la medida en que afecta la productividad de los sistemas de producción agropecuarios (Ramasamy \& Hiepe, 2009). De forma particular, cada una de las dimensiones de la seguridad alimentaria se ven afectadas, de modo que se pueden reducir: 1) la disponibilidad de alimentos por cuenta de la disminución en su producción; 2) el acceso a los alimentos, por daños en infraestructuras y disminución de ingresos; 3) la estabilidad en el suministro de alimentos, por cuenta de la variación en los precios de los alimentos y la dependencia de las importaciones; y 4) la utilización apropiada de los alimentos, por cuenta de los riesgos para la salud humana (Ramasamy \& Hiepe, 2009) (figura 3). 


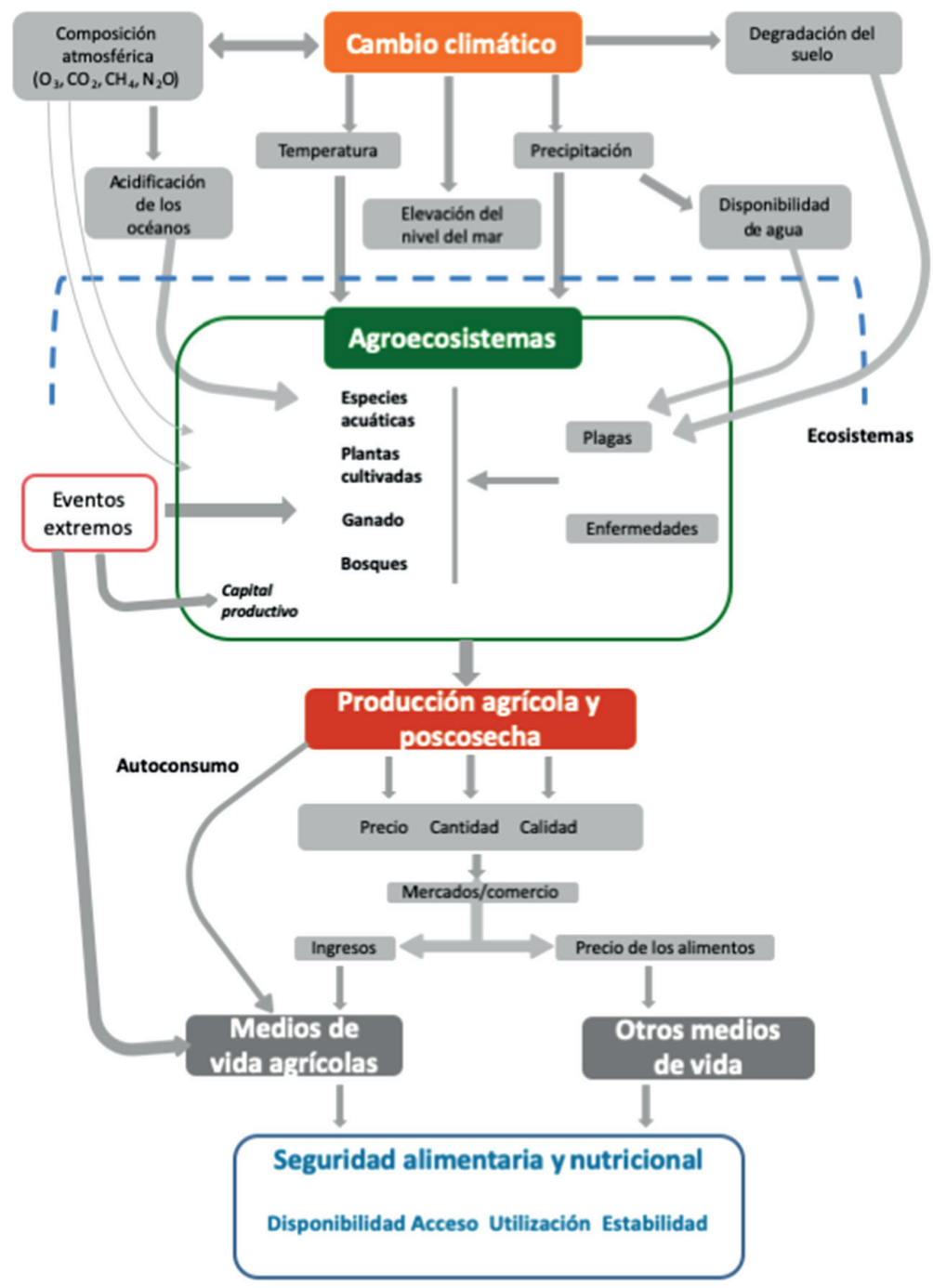

Figura 3. Representación esquemática de los efectos del cambio climático en la seguridad alimentaria Fuente: FAO (2016)

Son muchas las estrategias que se han planteado para hacer frente al cambio climático, dentro de las cuales se destacan las prácticas de agricultura sostenible, tales como: labranza cero o reducida; uso de variedades eficientes en el uso del nitrógeno; uso de variedades autóctonas y policultivos; agricultura de precisión; mejoramiento de praderas; manejo integrado de la fertilidad de suelos; mejoramiento de pastos forrajeros o leguminosas; cultivo de variedades tolerantes al calor; cosecha de agua y el riego localizado; control biológico de insectos plaga y la reducción en el uso 
de agroquímicos y fertilizantes (FAO, 2016). Estas estrategias de producción sostenible minimizan la presión sobre los recursos naturales y aumentan la resiliencia de los sistemas de producción, además, permiten allanar el camino hacia visiones diferentes o alternativas de la agricultura que, aunque no suficientemente entendidas, están siendo exploradas con fuerza en la actualidad.

El mundo enfrenta una nueva amenaza para la seguridad alimentaria y nutricional, que aumenta los riesgos de un desabastecimiento de alimentos, causados ya por el cambio climático. La existencia de una nueva enfermedad COVID-19, generada por el virus zoonótico SARS-CoV-2 y declarada pandemia por la Organización Mundial de la Salud (OMS), está teniendo profundas consecuencias en términos sanitarios, sociales y económicos.

\section{Enfermedad COVID-19 por infección del SARS-CoV-2}

Las condiciones impuestas por la pandemia generada por el virus SARS-CoV-2 a nivel global han impactado de forma transversal a prácticamente todos los ámbitos de la vida humana. No obstante, algunos de ellos han sido —y serán— afectados de una forma más evidente. Este es el caso de la seguridad y la soberanía alimentaria, que han sido preocupaciones desde hace ya varias décadas para los gobiernos de todo el mundo y que ahora constituyen derroteros concretos, incluso en aquellos países en los que el hambre y la desnutrición eran retos relativamente fáciles de afrontar. De hecho, en los países con mayores índices de pobreza multidimensional la pandemia supone un panorama de manejo crítico.

La pandemia, además, afecta los procesos de suministro y demanda de alimentos, principalmente por las interrupciones en la cadena de suministro, por cuenta de las medidas de contención del virus SARS-CoV-2. Esto trae consigo un incremento en la pérdida de alimentos (principalmente perecederos), el aumento de consumo de dietas no saludables (principalmente no perecederos), el incremento de los precios de los alimentos, la pérdida de empleos, la disminución de ingresos y, consecuentemente, un aumento en la inseguridad alimentaria.

\section{La seguridad y soberanía alimentaria y los ODS}

En la resolución aprobada por la Asamblea General de la ONU el 27 de julio de 2012, se dispuso de una comisión para la construcción de los llamados Objetivos de Desarrollo Sostenible considerando, entre otros, el compromiso relativo al derecho de toda persona a tener acceso a alimentos sanos, suficientes y nutritivos, y en el marco del respeto de la soberanía nacional de cada país sobre 
sus recursos naturales, teniendo en cuenta sus circunstancias, objetivos, responsabilidades y prioridades nacionales y el margen de acción de sus políticas con respecto a las tres dimensiones del desarrollo sostenible (Resolución 66/288 de la Asamblea General "El futuro que queremos", del 27 de julio de 2012).

Es así como en la resolución aprobada por la Asamblea General de la ONU el 25 de septiembre de 2015, se adoptó la Agenda 2030 para el Desarrollo Sostenible (Resolución 70/1 de la Asamblea General "Transformar nuestro mundo: la agenda 2030 para el desarrollo Sostenible”, del 25 de septiembre de 2015), que planteó 17 objetivos, con 169 metas que cubren los ámbitos económico, social y ambiental. Estos objetivos se listan a continuación:

- $\quad$ ODS 1: Erradicar la pobreza en todas sus formas en todo el mundo.

- ODS 2: Poner fin al hambre, conseguir la seguridad alimentaria, una mejor nutrición y promover la agricultura sostenible.

- ODS 3: Garantizar una vida saludable y promover el bienestar para todos y todas en todas las edades.

- ODS 4: Garantizar una educación de calidad inclusiva y equitativa, y promover las oportunidades de aprendizaje permanente para todos.

- ODS 5: Alcanzar la igualdad entre los géneros y empoderar a todas las mujeres y niñas.

- ODS 6: Garantizar la disponibilidad y la gestión sostenible del agua y el saneamiento para todos.

- ODS 7: Asegurar el acceso a energías asequibles, fiables, sostenibles y modernas para todos.

- ODS 8: Fomentar el crecimiento económico sostenido, inclusivo y sostenible, el empleo pleno y productivo, y el trabajo decente para todos.

- ODS 9: Desarrollar infraestructuras resilientes, promover la industrialización inclusiva y sostenible, y fomentar la innovación.

- ODS 10: Reducir las desigualdades entre países y dentro de ellos.

- ODS 11: Conseguir que las ciudades y los asentamientos humanos sean inclusivos, seguros, resilientes y sostenibles.

- ODS 12: Garantizar las pautas de consumo y de producción sostenibles.

- ODS 13: Tomar medidas urgentes para combatir el cambio climático y sus efectos.

- ODS 14: Conservar y utilizar de forma sostenible los océanos, mares y recursos marinos para lograr el desarrollo sostenible.

- ODS 15: Proteger, restaurar y promover la utilización sostenible de los ecosistemas terrestres, gestionar de manera sostenible los bosques, 
combatir la desertificación y detener y revertir la degradación de la tierra, además, frenar la pérdida de diversidad biológica.

- ODS 16: Promover sociedades pacíficas e inclusivas para el desarrollo sostenible, facilitar acceso a la justicia para todos y crear instituciones eficaces, responsables e inclusivas a todos los niveles.

- ODS 17: Fortalecer los medios de ejecución y reavivar la alianza mundial para el desarrollo sostenible.

En resolución aprobada por la Asamblea General el 6 de julio de 2017, se puso de relieve la necesidad de datos desglosados de calidad, accesibles, oportunos y fiables para ayudar a medir los progresos y asegurar que nadie se quede atrás en el logro de los ODS. En consecuencia, se aprobó el marco de indicadores mundiales para los Objetivos de Desarrollo Sostenible y las metas de la Agenda 2030 para el Desarrollo Sostenible, elaborado por el Grupo Interinstitucional y de Expertos sobre los Indicadores de los Objetivos de Desarrollo Sostenible.

Para que los Objetivos de Desarrollo Sostenible se logren de forma exitosa, se requieren procesos efectivos de monitoreo, revisión y seguimiento. Desde la adopción de la Agenda 2030, la FAO es la agencia de la ONU encargada de custodiar 21 indicadores para los ODS relacionados con la seguridad alimentaria y nutricional $(2,5,6,12,14$ y 15$)$ a través de materiales destinados a promover el conocimiento y la comprensión de estos indicadores (FAO, 2020a).

Para efectos del presente documento, se tomarán como punto de referencia estos mismos objetivos para identificar el papel actual o potencial de las FF. MM. en la contribución de la soberanía y seguridad alimentaria. Para esto se dará una breve descripción de cada indicador y una corta reseña de su estado en Colombia. Posteriormente, se presentarán los alcances del accionar de las Fuerzas Militares al respecto.

\section{Indicador 1. Prevalencia de la subalimentación}

La prevalencia de la subalimentación es una estimación de la proporción de la población cuyo consumo habitual de alimentos es insuficiente para proporcionarle los niveles de energía alimentaria necesarios para llevar una vida normal, activa y sana. Se expresa como porcentaje. La meta para el año 2030 es poner fin al hambre y asegurar el acceso de todas las personas, en particular los pobres y las personas en situaciones de vulnerabilidad, incluidos los niños menores de 1 año, a una alimentación sana, nutritiva y suficiente durante todo el año. La prevalencia de subalimentación en 2019 en el mundo fue de 8,9\%, en Latinoamérica y el Caribe de 7,3\%, y en Colombia de 5,5\% (FAO, 2020a). 


\section{Indicador 2. Prevalencia de inseguridad alimentaria moderada o grave en} la población, según la Escala de Experiencia de Inseguridad Alimentaria

Este indicador proporciona estimaciones internacionalmente comparables de la proporción de la población que tiene dificultades moderadas o graves para acceder a los alimentos. La escala de experiencia de inseguridad alimentaria mide la gravedad de la inseguridad alimentaria que padecen los individuos o las familias sobre la base de entrevistas directas. La meta asociada es la misma que para el indicador anterior. La prevalencia de inseguridad alimentaria moderada o severa en el mundo es de 25,363\% (FAO, 2020b).

Indicador 3. Volumen de producción por unidad de trabajo según el tamaño de la empresa agropecuaria/pastoral/silvícola

Este indicador se refiere al valor de la producción por unidad de mano de obra operada por pequeños productores en los sectores agrícola, ganadero y forestal. Se producirán datos en función del tamaño de las explotaciones. El indicador medirá los progresos hacia la consecución de la meta 2.3 de los ODS, que indica que para el 2030 se duplicará la productividad agrícola y los ingresos de los productores de alimentos en pequeña escala, en particular las mujeres, los pueblos indígenas, los agricultores familiares, los ganaderos y los pescadores. Todo ello, entre otras cosas, mediante un acceso seguro y equitativo a las tierras, a otros recursos e insumos de producción y a los conocimientos, los servicios financieros, los mercados y las oportunidades para añadir valor y obtener empleos no agrícolas. En este indicador aún no hay datos concretos para Colombia (FAO, 2020b).

\section{Indicador 4. Ingresos medios de los productores de alimentos en pequeña escala, desglosado por sexo y condición de indígena}

Este indicador trata de la media de ingresos de los productores de alimentos en pequeña escala, empleados en los sectores agropecuario, ganadero y forestal. Se utilizarán datos desglosados por sexo y condición indígena (FAO, 2020c). Este indicador también medirá los avances hacia la meta 2.3. En este indicador aún no hay datos concretos para Colombia.

\section{Indicador 5. Porcentaje de la superficie agrícola cultivada siguiendo prác-} ticas agrícolas sostenibles

La superficie agrícola en que se practica una agricultura productiva y sostenible refleja las tres dimensiones de la producción sostenible: ambiental, económica y social. El instrumento de medición (encuestas agrícolas) brinda a los países la flexi- 
bilidad para determinar las prioridades y los desafíos en las tres dimensiones de la sostenibilidad. Las tierras en que se practica una agricultura productiva y sostenible serán las explotaciones que cumplan con los indicadores seleccionados en las tres dimensiones. Este indicador medirá los progresos hacia la consecución de la meta 2.4 de los ODS, referida a que en el año 2030 se deberá asegurar la sostenibilidad de los sistemas de producción de alimentos y aplicar prácticas agrícolas resilientes que: aumenten la productividad y la producción; contribuyan al mantenimiento de los ecosistemas; fortalezcan la capacidad de adaptación al cambio climático, los fenómenos meteorológicos extremos, las sequías, las inundaciones y otros desastres; y mejoren progresivamente la calidad de la tierra y el suelo. En este indicador aún no hay datos concretos para Colombia (FAO, 2020c).

\section{Indicador 6. Indice del enriquecimiento de los cultivos mediante colec- ciones ex situ}

Los recursos genéticos vegetales para la alimentación y la agricultura preservados en instalaciones de conservación a medio y largo plazo (ex situ en bancos de germoplasma) representa el medio más fiable de conservar los recursos genéticos en el mundo. Este indicador mide los avances en la realización de la meta 2.5, orientada a mantener la diversidad genética de las semillas, las plantas cultivadas y los animales de granja y domesticados, así como de sus correspondientes especies silvestres. Esto, entre otras cosas, mediante una buena gestión y diversificación de los bancos de semillas y plantas a nivel nacional, regional e internacional, la promoción del acceso a los beneficios que se deriven de la utilización de los recursos genéticos y los conocimientos tradicionales conexos y su distribución justa y equitativa, según lo convenido internacionalmente (FAO, 2020e). A nivel global hay 5.419.423 recursos genéticos vegetales asegurados para la alimentación y la agricultura a mediano y largo plazo. En Latinoamérica y el Caribe este valor es de 405.601 recursos, y en Colombia es de 16.858 recursos. Este valor es extremadamente bajo si se compara con el de Brasil (188.304), Estados Unidos (582.149) o el Reino Unido (834.536).

Indicador 7. Porcentaje de cultivos y razas locales y sus variedades silvestres, clasificados según su situación de riesgo, ausencia de riesgo o un nivel de riesgo de extinción desconocido

Este indicador presenta la proporción de razas y variedades locales consideradas en riesgo de extinción en un momento determinado, así como las tendencias. Este indicador también mide los avances hacia la realización de la meta del 
ODS 2.5. En contraste con el indicador anterior, el porcentaje de razas locales y variedades silvestres en riesgo en Colombia es del 25\%, mientras que en Brasil es de 57\%, en Estados unidos es de 91\% y en el Reino Unido es de 87\% (FAO, 2020e).

\section{Indicador 8. Indice de orientación agrícola para los gastos públicos}

El índice de orientación agrícola (IOA) se define como la proporción del gasto público destinada a la agricultura dividida por la proporción del producto interno bruto (PIB) correspondiente a la agricultura, entendiendo por agricultura los sectores de la agricultura, la silvicultura, la pesca y la caza. La medida es un índice sin moneda, que se calcula como la razón entre estas dos proporciones, este indicador mide los progresos hacia la consecución de la meta 2.a de los ODS, relacionado con aumentar, incluso mediante una mayor cooperación internacional, las inversiones en infraestructura rural, investigación y servicios de extensión agrícola, desarrollo tecnológico y bancos de genes de plantas y ganado, con el fin de mejorar la capacidad de producción agropecuaria en los países en desarrollo, particularmente en los países menos adelantados. A nivel global, este indicador registra un valor de 0,28 y en Latinoamérica y el Caribe está en 0,25 (FAO, 2020f). En este indicador aún no hay datos concretos para Colombia.

\section{Indicador 9. Indicador de anomalías en los precios de los alimentos}

El indicador de anomalías en los precios de los alimentos propuesto mide el número de "anomalías en los precios", que se producen en la serie de precios de un producto alimenticio dado durante un período determinado. Este indicador mide los progresos hacia la consecución de la meta 2.c de los ODS, dirigida a la adopción de medidas para asegurar el buen funcionamiento de los mercados de productos básicos alimentarios y sus derivados, así como facilitar el acceso oportuno a la información sobre los mercados, incluso sobre las reservas de alimentos, con el fin de ayudar a limitar la extrema volatilidad de los precios de los alimentos. En Colombia, este valor es excepcionalmente alto para el maíz $(1,1)$ ubicándose, junto con Haití, en el primer lugar en Latinoamérica y el Caribe. Este indicador es moderadamente alto para el arroz $(0,6)$, lo que pone a Colombia en el tercer lugar después de Haití y México (FAO, 2020g). 
Indicador 10. Porcentaje del total de la población agrícola con derechos de propiedad o derechos seguros sobre las tierras agrícolas, desglosada por sexo (a); y proporción de mujeres entre los propietarios de tierras agricolas, o titulares de derechos sobre tierras agrícolas, desglosada por tipo de tenencia (b)

Este indicador se divide en dos subindicadores. La parte (a) es una medida de incidencia que mide la prevalencia de los derechos de propiedad o derechos seguros sobre tierras agrícolas en la población de referencia; la parte (b) mide la proporción de mujeres entre los propietarios de terrenos agrícolas o titulares de derechos sobre tierras agrícolas. Por consiguiente, puede utilizarse para el seguimiento de la infrarrepresentación de las mujeres entre los propietarios o titulares de terrenos agrícolas. Este indicador medirá, de facto, los progresos hacia la consecución de la meta 5.a de los ODS, orientado a emprender reformas que otorguen a las mujeres igualdad de derechos a los recursos económicos, así como acceso a la propiedad, el control de la tierra y otros tipos de bienes, los servicios financieros, la herencia y los recursos naturales, de conformidad con las leyes nacionales. Para Colombia aún no hay datos al respecto (FAO, 2020h).

Indicador 11. Porcentaje de países en que el ordenamiento jurídico (incluido el derecho consuetudinario) garantiza la igualdad de derechos de la mujer a la propiedad y/o el control de la tierra

El indicador recoge todos los objetivos normativos nacionales, los proyectos de disposiciones, las disposiciones jurídicas y la legislación de aplicación existentes que reflejan buenas prácticas en cuanto a garantizar la igualdad de derechos de la mujer respecto de la propiedad o el control de las tierras. Este indicador también mide los progresos hacia la consecución de la meta 5.a de los ODS y se valora entre 1 y 6 , siendo 1 el más bajo y 6 el más alto. Colombia tiene en este indicador en 6 , por encima de países como Suiza (4) y Jordán (1) (FAO, 2020i).

\section{Indicador 12. Cambio porcentual en la eficiencia del uso del agua con el tiempo}

La eficiencia en el uso del agua a nivel nacional es la suma de las eficiencias en los principales sectores económicos ponderadas en función de la proporción de agua extraída por cada sector respecto de las extracciones totales. Este indicador mide los cambios en la eficiencia en el uso del agua y tiene la finalidad de abordar el componente económico de la meta 6.4 de los ODS, encaminado a aumentar 
considerablemente el uso eficiente de los recursos hídricos en todos los sectores y asegurar la sostenibilidad de la extracción y el abastecimiento de agua dulce, para hacer frente a la escasez de agua y reducir considerablemente el número de personas que sufren la falta de este líquido. El indicador se mide en términos del valor ańadido por agua extraída $\left(\mathrm{USD} / \mathrm{m}^{3}\right)$. Colombia no ha tenido incrementos significativos en este sentido en los últimos diez años, manteniendo un valor que oscila entre 18 y $19 \mathrm{USD} / \mathrm{m}^{3}$, mientras que Estados Unidos ha incrementado en el mismo tiempo de 31 a $41 \mathrm{USD} / \mathrm{m}^{3}$, Reino unido de 181 a $3165 \mathrm{USD} / \mathrm{m}^{3}$. Brasil, por su parte, tiene un comportamiento muy similar al de Colombia (FAO, 2020j).

Indicador 13. Porcentaje del total de recursos hidricos disponibles utilizados, teniendo en cuenta las necesidades hídricas ambientales (nivel de estrés por escasez de agua)

El nivel de estrés hídrico es la razón entre el total de agua dulce extraída por los principales sectores económicos y el total de recursos hídricos renovables, teniendo en cuenta las necesidades ambientales de agua. Este indicador también se conoce como intensidad de extracción de agua y mide los progresos hacia la meta 6.4 de los ODS. El valor de este indicador para Colombia es de $2 \%$, constituyéndose como el tercero más bajo de todos los países de América Latina y el Caribe (FAO, 2020k).

\section{Indicador 14. Índice de la pérdida mundial de alimentos}

Este índice obedece a la meta del ODS 12.3, que tiene dos componentes, las pérdidas y el desperdicio, que están medidos por dos indicadores distintos. El primero de ellos se centra en las pérdidas de alimentos que se producen desde la producción hasta el nivel minorista (sin incluir este); el segundo mide el desperdicio de alimentos, que comprende los niveles minoristas y de consumo. Este último está aún en proceso de determinación, pero se estima que es la tercera parte de todo el alimento mundial. Por su parte, en el primero de ellos, cabe destacar que Latinoamérica y el Caribe tienen una pérdida de alimentos, entre poscosecha y distribución, de 11,6\%, mientras que en el mundo este valor es de $13,8 \%$ (FAO, 20201).

\section{Indicador 15. Proporción de poblaciones de peces que están dentro de niveles biológicamente sostenibles}

Este indicador mide la sostenibilidad de la pesca de captura marina mundial por su abundancia. Una población de peces cuya abundancia es igual o superior al nivel que puede producir el rendimiento máximo sostenible se clasifica como bioló- 
gicamente sostenible. Por el contrario, cuando la abundancia queda por debajo de este nivel, la población se considera biológicamente insostenible. El indicador mide los progresos hacia la consecución de la meta 14.4 de los ODS (FAO, 2020m), que busca: reglamentar eficazmente la explotación pesquera y poner fin a la pesca excesiva, la pesca ilegal, no declarada y no reglamentada; así como a las prácticas pesqueras destructiva. Además, tiene como fin aplicar planes de gestión con fundamento científico para restablecer las poblaciones de peces en el plazo más breve posible, al menos alcanzando niveles que puedan producir el máximo rendimiento sostenible de acuerdo con sus características biológicas. En el mundo, este índice ha disminuido dramáticamente de 90\% en 1974 a 65,85\% en 2017.

\section{Indicador 16. Progresos realizados por los paises en el grado de aplicación de instrumentos internacionales cuyo objetivo es combatir la pesca ilegal, no declarada y no reglamentada}

Este indicador pone el acento sobre los esfuerzos para luchar contra la pesca ilegal, no declarada y no reglamentada a través de una implementación efectiva de instrumentos internacionales clave. Este indicador mide los avances hacia la realización de la meta del ODS 14.6, que busca prohibir ciertas formas de subvenciones a la pesca que contribuyen a la sobrecapacidad y la pesca excesiva (FAO, 2020n). Para Colombia no hay datos al respecto.

\section{Indicador 17. Pesca sostenible como porcentaje del PIB en los pequeños Estados insulares en desarrollo, los países menos adelantados y todos los países}

La finalidad de este indicador es medir el valor de la pesca sostenible. Se expresa como porcentaje del PIB del país. Se producen datos sobre todos los países y se agregan los relativos a los pequeños Estados insulares en desarrollo y los países menos adelantados. El indicador mide los progresos hacia la consecución de la meta 14.7 de los ODS, tendiente a aumentar los beneficios económicos que los pequeños Estados insulares en desarrollo y los países menos adelantados obtienen del uso sostenible de los recursos marinos, en particular mediante la gestión sostenible de la pesca, la acuicultura y el turismo. Este indicador tiene un valor a nivel global de 0,0914\%, en Latinoamérica y el Caribe de 0,1096\%, y en Colombia de 0,0003 (FAO, 2020ñ). 


\section{Indicador 18. Progresos realizados por los países en el grado de aplicación de un marco jurídico, reglamentario, normativo o institucional que reco- nozca y proteja los derechos de acceso de la pesca en pequeña escala}

Se trata de un indicador compuesto, calculado sobre la base de los esfuerzos que están realizando los países con objeto de aplicar determinadas disposiciones fundamentales de las directrices voluntarias para lograr la sostenibilidad de la pesca en pequeña escala en el contexto de la seguridad alimentaria y la erradicación de la pobreza. Este indicador mide el aspecto relacionado con los "derechos de acceso" de la meta 14.b de los ODS, dirigida a facilitar el acceso de los pescadores artesanales a los recursos marinos y los mercados. Este indicador se mide en una escala de 1 (bajo) a 5 (alto); Colombia muestra un nivel de implementación de 5 (FAO, 2020o).

\section{Indicador 19. Superficie forestal como proporción de la superficie total}

Este indicador mide la proporción de la superficie terrestre mundial que tiene cobertura forestal y se expresa como porcentaje. Los cambios en la superficie forestal reflejan cambios en la demanda de tierra para otros usos y pueden contribuir a la determinación de prácticas insostenibles en los sectores forestal y agrícola. El indicador mide los progresos hacia la consecución de la meta 15.1 de los ODS, centrada en asegurar la conservación, el restablecimiento y el uso sostenible de los ecosistemas terrestres y los ecosistemas interiores de agua dulce y sus servicios, en particular los bosques, los humedales, las montańas y las zonas áridas. A 2015, en el mundo, este indicador alcanzó el 30,7\%, mientras que en Latinoamérica y el Caribe bajó de 49,1\%, en el año 2000, a 46,4\%, en el año 2015 (FAO, 2020p).

\section{Indicador 20. Cubierta forestal en el marco de la ordenación sostenible de los bosques}

Esteindicador midelos progresos hacialagestión forestal sostenible por mediode cincosubindicadores: 1) tasanetadecambioanualdelasuperficieforestal;2) existencias forestales de biomasa porencimadel suelo $(\mathrm{t} / \mathrm{ha}) ; 3$ ) proporción dela superficieforestal en las áreas protegidas legalmente establecidas; 4) proporción de la superficie forestal sometida a un plan de gestión forestal de largo plazo como ayuda a la interpretación; y 5) superficie de bosques certificados. El indicador contribuye a seguir los progresos hacia la consecución de la meta 15.2 de los ODS, enfocada en promover la puesta en práctica de la gestión sostenible de todos los tipos de bosques, detener la deforestación, recuperar los bosques degradados y aumentar considerablemente la forestación y la reforestación a nivel mundial. Latinoamérica y el Caribe presentan 
cambios positivos en los subindicadores 2, 3 y 4, y no presentan cambios en los subindicadores 1 y 5 . A nivel mundial, 1 y 2 no presentan cambios significativos, el 3 y 4 presentan cambios positivos, y el 5 presentó cambios negativos (FAO, 2020q).

\section{Indicador 21. Índice de cobertura verde de las montañas}

El índice de cobertura verde de las montañas mide los cambios en la superficie de vegetación verde (bosques, arbustos, tierras de pastoreo y tierras de cultivo) de las zonas montañosas. Esta información ayudará a determinar el estado de conservación de los entornos montańosos, con el objeto de medir los progresos hacia la consecución de la meta 15.4 de los ODS, orientada a asegurar la conservación de los ecosistemas montańosos, incluida su diversidad biológica, con el fin de mejorar su capacidad de proporcionar beneficios esenciales para el desarrollo sostenible. En Latinoamérica y el Caribe el porcentaje de cobertura vegetal en las montańas es del $83 \%$, mientras que para el mundo es del 76\% (FAO, 2020r).

\section{Acción Integral, un vínculo clave entre los ODS y las FF. MM.}

El señor General Valencia Tovar, líder en la implementación inicial de estrategias no militares, que hacían énfasis en un tratamiento social integral del conflicto, definió la Acción Integral como el

desarrollo y coordinación permanente de acciones políticas económicas, sociales y militares encaminadas a fortalecer las estructuras básicas del Estado y garantizar la defensa la protección de los derechos y libertades de la sociedad para que los habitantes de Colombia, haciendo uso de la libertad y dentro de los derechos y deberes constitucionales, alcance el goce de una paz justa, digna y duradera, que permita un adecuado desarrollo y progreso. (Comando General de Fuerzas Militares, 2017)

Actualmente, se plantea la configuración de la Doctrina de Acción Integral como la materialización y concreción de una serie de iniciativas que trascienden el concepto tradicional de seguridad (Castillo \& Niño, 2016). La Acción Integral es una herramienta de gestión y coordinación, utilizada por las FF. MM. y por el Gobierno nacional para la consolidación de territorios que fueron controlados por los grupos al margen de la ley (Mejía, 2015). Esto es especialmente importante, si se considera que los estudios militares contemporáneos sugieren la implementación de nuevas estrategias de mayor alcance para las FF. MM., en las que se incluyen elementos políticos, sociales y económicos, logrando superar la concepción ortodoxa de seguridad nacional (Castillo \& Niño, 2016). 
Basados en la propuesta del Programa de Naciones Unidas para el Desarrollo (PNUD) (1994), sobre el concepto de "seguridad humana", Castillo y Niño (2016) hicieron énfasis en las diferentes categorías que la componen: seguridad económica, alimentaria, de salud, ambiental, personal, de la comunidad y política. Así, la capacidad instalada de las FF. MM. en sus operaciones de Acción Integral se convierten en un instrumento que puede contribuir al cumplimiento de los objetivos y metas de los Planes de Desarrollo (Téllez, 2017) de los gobiernos, porque apunta a convertir a las FF. MM. en agentes dinamizadores del crecimiento del país, contribuyendo a fomentar el desarrollo social, económico y la inversión, alineados con la protección del medioambiente y los recursos naturales, para las generaciones actuales y futuras (Comando General de Fuerzas Militares, 2017).

Este contexto pone de manifiesto el importante papel que tienen las FF. MM. para el avance del país en los ODS, especialmente en aquellas regiones donde la presencia del Estado aún es débil y la seguridad de sus habitantes no está completamente garantizada. Precisamente, uno de sus principales componentes de seguridad humana: el de la seguridad alimentaria, también puede verse beneficiado por la acción de las FF. MM. Estos beneficios redundan también en un cuidado de la soberanía alimentaria, en razón del impacto particular de las FF. MM. en cada territorio. Por tal motivo, es importante identificar de qué forma las capacidades de las FF. MM. se vinculan con los 21 indicadores de los ODS 2, 5, 6, 12, 14 y 15, que se relacionan con la seguridad alimentaria y nutricional.

En el Manual de Acción integral Conjunta (Comando General de las fuerzas Militares, 2017) se describen las cinco capacidades particulares en las cuales se enmarcan las potencialidades generales de las FF. MM. para este propósito. A continuación, se resumen con el propósito de contextualizar el análisis posterior.

Capacidad 1. Difusión de mensajes e información a todas las comunidades y puntos del territorio nacional, con el propósito de dar a conocer programas, planes y entidades u organizaciones que contribuyen al desarrollo socioeconómico del país.

- $\quad$ Educación para el trabajo comunitario.

- Prevención y promoción de la salud.

- Apoyo al desarrollo productivo y empresarial.

- Apoyo a la producción y difusión de programas comunitarios alternativos de reconstrucción social.

- Sistema integrado de desarrollo marítimo y fluvial. 
Capacidad 2. Apoyar a la población (comunidades y sociedad) en el mejoramiento de su calidad de vida, en aras de contribuir con el desarrollo integral de las regiones, de acuerdo con los planes gubernamentales.

- Jornadas de Cooperación Cívico-Militares.

- Empleo de Ingenieros Militares.

- Fomento del desarrollo turístico y deportivo, marítimo y fluvial.

Capacidad 3. Establecer y promover relaciones con las demás instituciones del Estado, autoridades gubernamentales, comunidades, gremios, empresas privadas, etc., en todo el territorio nacional.

- Dirección y liderazgo.

- Formación y capacitación en Acción Integral.

- Mantenimiento y protección red energética y vial.

- Diplomacia naval para el desarrollo económico.

- Investigación y desarrollo tecnológico.

- Desarrollo, investigación marítima y fluvial.

Capacidad 4. Integrar los medios y competencias de las Fuerzas Militares con las instituciones del Estado para apoyar el cumplimiento de sus fines esenciales.

- Apoyo de la defensa a la autoridad civil.

- Estabilidad.

- Apoyo a la conectividad.

- Transporte terrestre, fluvial y aéreo.

- Desminado humanitario.

- Jornadas de apoyo al desarrollo.

- Aerografía.

- Desarrollo integral marítimo en offshore, puertos y canales.

- Ingeniería Aeronáutica.

- Proyectos de investigación y desarrollo tecnológico.

- Protección y rescate de especies naufragas.

- Vigilancia aérea a la red energética y vial.

- Apoyo a la capacitación en actividades náuticas.

Capacidad 5. Potenciar las capacidades militares de prevención y atención de desastres, así como contribuir a la protección y preservación del medioambiente. 
- Extinción de incendios.

- Búsqueda y rescate de personas, embarcaciones o aeronaves.

- Evacuación y traslado médico, aeromédico, marítimo y fluvial.

- Búsqueda y rescate de embarcaciones.

- Apoyo en atención de emergencia y crisis.

- Vigilancia, reconocimiento y control vulcanológico.

- Protección y defensa del medioambiente y recursos humanos.

En la tabla 1 se presentan las posibles relaciones entre las capacidades de Acción Integral de las FF. MM. y los 21 indicadores de los ODS 2, 5, 6, 12, 14 y 15 que se relacionan con la seguridad alimentaria y nutricional. Para el análisis se consideraron las posibles relaciones directas o indirectas, así como la contribución potencial de cada capacidad de Acción Integral a cada indicador, en atención a que están diseñados para la generación de estadísticas a nivel del país.

Los resultados indican que las Capacidades de Acción Integral 3 y 4 están fuertemente asociadas con los indicadores que vinculan a la seguridad alimentaria con los ODS. Esto indica que el relacionamiento de las FF. MM. con instituciones estatales, autoridades gubernamentales, comunidades, gremios, empresas privadas a nivel territorial, puede constituirse como una estrategia importante de contribución a la seguridad y soberanía alimentaria en el país.

De otra parte, es evidente la relación entre todas las capacidades de Acción Integral con el manejo del recurso hídrico y la pesca. Este resultado es consistente con los esfuerzos estatales que actualmente ubican a Colombia por fuera del grupo de países con mayores riesgos por estrés hídrico y pérdida de recursos genéticos marítimos. No obstante, es importante abordar los datos con precaución, por cuanto las estadísticas son relativas y no aseguran que los recursos hídricos y marinos estén fuera de peligro.

Cabe anotar que las capacidades de Acción Integral tienen una relación más débil con el fomento de la producción de alimentos a partir de la agricultura, lo que contrasta con el hecho de que Colombia es un país con vocación agrícola. De hecho, el país es considerado como uno de los pocos con capacidad de incrementar su producción agrícola, a tal punto que es considerado como una despensa de alimentos para el mundo futuro. Lo anterior pone de relieve una oportunidad importante de desarrollo para las comunidades con débil presencia estatal, a las que las FF. MM. pueden impactar positivamente mejorando su seguridad, particularmente la alimentaria. 
Tabla 1. Relación entre capacidades de Acción Integral, las FF. MM. y 21 indicadores FAO para seguridad alimentaria según los ODS

\begin{tabular}{|c|c|c|c|c|c|}
\hline Indicadores & Capacidad 1 & Capacidad 2 & Capacidad 3 & Capacidad 4 & Capacidad 5 \\
\hline \multirow{3}{*}{\multicolumn{6}{|c|}{\begin{tabular}{|l|l|} 
Indicador 1. Prevalencia de la subalimentación & \\
Indicador 2. Prevalencia de inseguridad alimentaria moderada o grave en la población, \\
según la Escala de Experiencia de Inseguridad Alimentaria
\end{tabular}}} \\
\hline & & & & & \\
\hline & & & & & \\
\hline \multicolumn{6}{|l|}{$\begin{array}{l}\text { Indicador 3. Volumen de producción por unidad de trabajo según el tamańo de la } \\
\text { empresa agropecuaria/pastoral/silvícola }\end{array}$} \\
\hline \multicolumn{6}{|l|}{$\begin{array}{l}\text { Indicador 4. Ingresos medios de los productores de alimentos en pequeńa escala, } \\
\text { desglosado por sexo y condición de indígena }\end{array}$} \\
\hline \multicolumn{6}{|l|}{$\begin{array}{l}\text { Indicador 5. Porcentaje de la superficie agrícola cultivada siguiendo prácticas agrí́colas } \\
\text { sostenibles }\end{array}$} \\
\hline \multicolumn{6}{|l|}{ Indicador 6. Índice del enriquecimiento de los cultivos mediante colecciones ex situ } \\
\hline \multicolumn{6}{|l|}{$\begin{array}{l}\text { Indicador 7. Porcentaje de cultivos y razas locales y sus variedades silvestres, } \\
\text { clasificados según su situación de riesgo, ausencia de riesgo o un nivel de riesgo de } \\
\text { extinción desconocido }\end{array}$} \\
\hline \multicolumn{6}{|l|}{ Indicador 8. Índice de orientación agrícola para los gastos públicos } \\
\hline \multicolumn{6}{|l|}{ Indicador 9. Indicador de anomalías en los precios de los alimentos } \\
\hline \multicolumn{6}{|l|}{$\begin{array}{l}\text { Indicador 10. Porcentaje del total de la población agrícola con derechos de propiedad } \\
\text { o derechos seguros sobre las tierras agrícolas, desglosada por sexo (a); y proporción de } \\
\text { mujeres entre los propietarios de tierras agrícolas, o titulares de derechos sobre tierras } \\
\text { agrícolas, desglosada por tipo de tenencia (b). }\end{array}$} \\
\hline \multicolumn{6}{|l|}{$\begin{array}{l}\text { Indicador 11. Porcentaje de países en que el ordenamiento jurídico (incluido el } \\
\text { derecho consuetudinario) garantiza la igualdad de derechos de la mujer a la propiedad } \\
\text { y/o el control de la tierra. }\end{array}$} \\
\hline \multicolumn{6}{|l|}{ Indicador 12. Cambio porcentual en la eficiencia del uso del agua con el tiempo } \\
\hline \multicolumn{6}{|l|}{$\begin{array}{l}\text { Indicador 13. Porcentaje del total de recursos hídricos disponibles utilizados, teniendo } \\
\text { en cuenta las necesidades hídricas ambientales (nivel de estrés por escasez de agua) }\end{array}$} \\
\hline \multicolumn{6}{|l|}{ Indicador 14. Índice de la pérdida mundial de alimentos } \\
\hline \multicolumn{6}{|l|}{$\begin{array}{l}\text { Indicador 15. Proporción de poblaciones de peces que están dentro de niveles } \\
\text { biológicamente sostenibles }\end{array}$} \\
\hline \multicolumn{6}{|l|}{\begin{tabular}{|l|} 
Indicador 16. Progresos realizados por los países en el grado de aplicación de \\
instrumentos internacionales cuyo objetivo es combatir la pesca ilegal, no declarada y \\
no reglamentada
\end{tabular}} \\
\hline \multicolumn{6}{|l|}{$\begin{array}{l}\text { Indicador 17. Pesca sostenible como porcentaje del PIB en los pequeños Estados } \\
\text { insulares en desarrollo, los paises menos adelantados y todos los países }\end{array}$} \\
\hline \multicolumn{6}{|l|}{\begin{tabular}{|l|} 
Indicador 18. Progresos realizados por los países en el grado de aplicación de un \\
marco jurídico, reglamentario, normativo o institucional que reconozca y proteja los \\
derechos de acceso de la pesca en pequeńa escala
\end{tabular}} \\
\hline \multicolumn{6}{|l|}{ Indicador 19. Superficie forestal como proporción de la superficie total } \\
\hline Indicador 20. Cubierta forestal en el marco de la ordenación sostenible de los bosques & & & & & \\
\hline , & & & & & \\
\hline
\end{tabular}

\begin{tabular}{l} 
Posibles relaciones: \\
\hline Relación directa \\
Relación indirecta \\
\\
No hay relación evidente
\end{tabular}

\section{Conclusión}

La concepción de seguridad alimentaria ha venido evolucionando hasta llegar a un concepto integral en torno a la garantía de acceso a alimentos de calidad. Por tanto, recientemente se ha acuńado el concepto de 'seguridad alimentaria y nutricional'. No obstante, hay un segundo concepto que vincula las características particulares de los territorios a la alimentación, y se define como 'soberanía alimen- 
taria'. Independientemente del concepto, el aumento de la población mundial y el cambio climático retan la capacidad de las naciones para alimentar a sus habitantes. Situación que se ha acentuado con la pandemia debida a la COVID-19 producida por el virus SARS-CoV-2.

Por otra parte, los ODS se constituyen como la respuesta de los países organizados frente a los retos del desarrollo. Resulta de la mayor importancia para Colombia, considerada una despensa de alimentos para el mundo, propender por el mejoramiento de aquellos indicadores de los ODS orientados a la seguridad alimentaria. Las FF. MM., como garantes de la seguridad en todo el territorio nacional, cumplen un papel estratégico tanto en la seguridad como en la soberanía alimentaria. El análisis de las capacidades de las FF. MM. frente a los indicadores de seguridad alimentaria alineados con los ODS, permitió evidenciar que el relacionamiento estratégico de las FF. MM. con organizaciones privadas o estatales puede constituirse como una estrategia importante de contribución a la seguridad y soberanía alimentaria en el país; no obstante, hay una oportunidad de impacto mayor, particularmente en las acciones tendientes a promover la producción de alimentos de origen agrícola.

\section{Referencias}

Castillo, A., \& Niño, C. (2016). La Doctrina de Acción Integral como política de seguridad en el posconflicto armado en Colombia. En C. Niño (Comp.), Perspectivas y prospectivas de la seguridad en Colombia (pp. 121-148). Universidad Santo Tomás.

Comando General de Fuerzas Militares. (2017). Manual de Acción Integral Conjunta. Imprenta y Publicaciones de las Fuerzas Militares.

European Coordination vía Campesina. (2018). jSoberanía alimentaria, ya! Una guía por la soberania alimentaria. https:/viacampesina.org/en/wp-content/uploads/sites/2/2018/02/FoodSovereignty-a-guide-ES-version-low-res.pdf

FAO, IFAD, Unicef, WFP \& WHO. (2020). The state of food security and nutrition in the world 2020: Transforming food systems for affordable healthy diets. FAO - Food and Agriculture Organization of The United Nations.

FAO. (2006). Seguridad alimentaria y nutricional Conceptos básicos. FAO - Food and Agriculture Organization of The United Nations. http://www.fao.org/3/a-at772s.pdf

FAO. (2011). Colombia se proyecta como una gran despensa agrícola. FAO - Food and Agriculture Organization of The United Nations. http://www.fao.org/in-action/agronoticias/detail/ es/c/507341/

FAO. (2016). Climate change and food security: risks and responses. FAO - Food and Agriculture Organization of The United Nations. http://www.fao.org/policy-support/tools-and-publications/resources-details/es/c/427091/ 
FAO. (2017). The future of food and agriculture: Trends and challenges. FAO - Food and Agriculture Organization of The United Nations. http://www.fao.org/3/a-i6583e.pdf

FAO. (2019). Los indicadores de los ODS bajo la custodia de la FAO: ¿̨uáles son las novedades? FAO - Food and Agriculture Organization of The United Nations. http://www.fao.org/members-gateway/news/detail/es/c/1252816/

FAO. (2020a). Poner fin al hambre, lograr la seguridad alimentaria y la mejora de la nutrición y promover la agricultura sostenible. FAO - Food and Agriculture Organization of The United Nations. http://www.fao.org/sustainable-development-goals/goals/goal-2/es/

FAO. (2020b). Indicador 2.1.2 - Prevalencia de inseguridad alimentaria moderada o grave en la población, según la Escala de Experiencia de Inseguridad Alimentaria. FAO - Food and Agriculture Organization of The United Nations. http://www.fao.org/sustainable-development-goals/indicators/212/es/

FAO. (2020c). Indicador 2.3.2 - Media de ingresos de los productores de alimentos en pequeña escala, desglosada por sexo y condición indígena. FAO - Food and Agriculture Organization of The United Nations. http://www.fao.org/sustainable-development-goals/indicators/232/es/

FAO. (2020e). Indicador 2.5.2 - Proporción de razas y variedades locales consideradas en riesgo de extinción. FAO - Food and Agriculture Organization of The United Nations. http://www.fao. org/sustainable-development-goals/indicators/252/es/

FAO. (2020f). Indicador 2.a.1 - Índice de orientación agrícola para el gasto público. FAO - Food and Agriculture Organization of The United Nations. http://www.fao.org/sustainable-development-goals/indicators/2a1/es/

FAO. (2020g). Indicador 2.c.1 - Indicador de anomalías en los precios de los alimentos. FAO - Food and Agriculture Organization of The United Nations. http://www.fao.org/sustainable-development-goals/indicators/2c1/es/

FAO. (2020h). Indicador 5.a.1 - (a) Proporción del total de la población agrícola con derechos de propiedad o derechos seguros sobre tierras agrícolas, desglosada por sexo; y (b) proporción de mujeres entre los propietarios o los titulares de derechos sobre tierras agrícolas, desglosada por tipo de tenencia. FAO - Food and Agriculture Organization of The United Nations. http:// www.fao.org/sustainable-development-goals/indicators/5a1/es/

FAO. (2020i). Indicador 5.a.2 - Proporción de países cuyo ordenamiento jurídico (incluido el derecho consuetudinario) garantiza la igualdad de derechos de la mujer a la propiedad o el control de las tierras. FAO - Food and Agriculture Organization of The United Nations. http://www.fao.org/ sustainable-development-goals/indicators/5a2/es/

FAO. (2020j). Indicador 6.4.1 - Cambio en el uso eficiente de los recursos hídricos con el paso del tiempo. FAO - Food and Agriculture Organization of The United Nations. http://www.fao.org/ sustainable-development-goals/indicators/641/es/

FAO. (2020k). Indicador 6.4.2 - Nivel de estrés hídrico: extracción de agua dulce en proporción a los recursos de agua dulce disponibles. FAO - Food and Agriculture Organization of The United Nations. http://www.fao.org/sustainable-development-goals/indicators/642/es/

FAO. (20201). Indicador 12.3.1 - Pérdidas y desperdicio mundiales de alimentos. FAO - Food and Agriculture Organization of The United Nations. http://www.fao.org/sustainable-development-goals/indicators/1231/es/

FAO. (2020m). Indicador 14.4.1 - Proporción de poblaciones de peces cuyos niveles son biológicamente sostenibles. FAO - Food and Agriculture Organization of The United Nations. http:// www.fao.org/sustainable-development-goals/indicators/1441/es/ 
FAO. (2020n). Indicador 14.6.1 - Grado de aplicación de instrumentos internacionales cuyo objetivo es combatir la pesca ilegal, no declarada y no reglamentada. FAO - Food and Agriculture Organization of The United Nations. http://www.fao.org/sustainable-development-goals/indicators/1461/es/

FAO. (2020ñ). Indicador 14.7 - Proporción del PIB correspondiente a la pesca sostenible en los pequeños Estados insulares en desarrollo, en los países menos adelantados y en todos los países. FAO - Food and Agriculture Organization of The United Nations. http://www.fao.org/sustainable-development-goals/indicators/1471/es/

FAO. (2020o). Indicador 15.1.1 - Superficie forestal en proporción a la superficie total. FAO - Food and Agriculture Organization of The United Nations. http://www.fao.org/sustainable-development-goals/indicators/1511/es/

FAO. (2020p). Indicador 2.c.1 - Indicador de anomalías en los precios de los alimentos. FAO - Food and Agriculture Organization of The United Nations. http://www.fao.org/sustainable-development-goals/indicators/2c1/es/

FAO. (2020q). Indicador 15.2.1 - Avances hacia la gestión forestal sostenible. FAO - Food and Agriculture Organization of The United Nations. http://www.fao.org/sustainable-development-goals/indicators/1521/es/

FAO. (2020r). Indicador 15.4.2 - Índice de cobertura verde de las montañas. FAO - Food and Agriculture Organization of The United Nations. http://www.fao.org/sustainable-development-goals/indicators/1542/es/

Fischer, G., Tubiello, F., Velthuizen, H., Van, \& Wiberg, D. (2007). Climate Change Impacts on Irrigation Water Requirements: Effects of Mitigation, 1990-2080. Technological Forecasting and Social Change, 74(7), 1083-1107. https://doi.org/10.1016/j.techfore.2006.05.021

Gornall, J., Betts, R., Burke, E., Clark, R., Camp, J., Willett, K., \& Wiltshire, A. (2010). Implications of Climate Change for Agricultural Productivity in The Early Twenty-First Century. Philosophical Transactions of The Royal Society, 365(1554), 2973-2989. https://doi.org/10.1098/ rstb.2010.0158

Guzmán-Barrón, C. (1997). El dumping en el comercio internacional. THEMIS-Revista de Derecho, (36), 137-141.

Hoekstra, A., \& Mekonnen, M. (2012). The Water Footprint of Humanity. PNAS, 109(9), 32323237. https://doi.org/10.1073/pnas.1109936109

IPCC. (2013). Summary for Policymakers. En T. Stocker, D. Qin, G. Plattner, M. Tignor, S. Allen, J. Boschung, A. Nauels, Y. Xia, V. Bex \& P. Midgley (Eds.), Climate Change 2013: The Physical Science Basis (pp. 3-29). Cambridge University Press.

Kissinger, G., Herold, M., \& De Sy, V.(2012). Drivers of Deforestation and Forest Degradation. Lexeme Consulting.

Macartan, B. (2017). Food Sovereignty: An Alternative Framework to The Narrower Concept of Food Security. https://www.researchgate.net/publication/316455982

Mejía, O. (2015). La acción integral: herramienta de gestión de los gobiernos municipales focalizados por la Política Nacional de Consolidación y Reconstrucción Territorial. Equidad y Desarrollo, 1(23), 127-145.

Newbold, T., Hudson, L., Hill, S., Contu, S., Lysenko, I., Senior, R., Börger, L., Bennett, D., Choimes, A., Collen, B., Day, J., De Palma, A., Díaz, S., Echeverria-Londońo, S., Edgar, M., 
Feldman, A., Garon, M., Harrison, M., Alhusseini, T., Ingram, D., \& Itescu, Y. (2015). Global effects of land use on local terrestrial biodiversity. Nature, 520, 45-50. https://doi.org/10.1038/ nature 14324

Organización de las Naciones Unidas. (2012). Resolución 66/288 de la Asamblea General "El futuro que queremos".

Organización de las Naciones Unidas. (2015). Resolución 70/1 de la Asamblea General “Transformar nuestro mundo: la agenda 2030 para el desarrollo Sostenible".

Padmavathy, K., \& Poyyamoli, G. (2011). Alternative Farming Techniques for Sustainable Food Production. Genetics, Biofuels and Local Farming Systems, 7, 367-424. https://doi. org/10.1007/978-94-007-1521-9

Programa de Naciones Unidas para el Desarrollo (PNUD) (1994). Un programa para la Cumbre Mundial sobre Desarrollo Social. Informe sobre desarrollo humano. http://hdr.undp.org/es/ informes/mundial/idh1994/

Proyecto Food Facility Honduras. (2011). Seguridad Alimentaria y Nutricional. Conceptos Básicos. http://www.fao.org/3/a-at772s.pdf

Ramasamy, S., \& Hiepe, C. (2009). Climate Change Impacts on Agriculture and Food Security and Disaster Risk Management as entry point for Climate Change Adaptation. EASYPol. http://www.fao.org/docs/up/easypol/778/climate-change_impacts_on_agric_food_security_ slides_077en.pdf

Ramankutty, N., Mehrabi, Z., Waha, K., Jarvis, L., Kremen, C., Herrero, M., \& Rieseberg,

L. H. (2018). Trends in global agricultural land use: implications for environmental

health and food security. Annual review of plant biology, 69, 789-815.

Smith, P., Bustamante, M., Ahammad, H., Clark, H., Dong, H., Elsiddig, E., Haberl, H., Harper, R., House, J., Jafari, M., \& Masera, O. (2014). Agriculture, Forestry and Other Land Use (AFOLU). En O. Edenhofer, R. Pichs-Madruga, Y. Sokona, E. Farahani, S. Kadner, K. Seyboth, A. Adler, I. Baum, S. Brunner, P. Eickemeier, B. Kriemann, J. Savolainen, S. Schlömer, C. von Stechow, T. Zwickel, \& J. Minx (Eds.), Climate Change 2014: Mitigation of Climate Change. Contribution of Working Group III to the Fifth Assessment Report of the Intergovernmental Panel on Climate Change (pp. 811-922). Cambridge University Press.

Téllez, C. (2017). Líneas de acción para la integración de las FF. MM., con el desarrollo territorial en el posacuerdo (Tesis de maestría). Universidad EAFIT.

The World Bank. (2015). Arable land (hectares per person). The World Bank. https://data.worldbank. org/indicator/AG.lnd.Arbl.HA.pc

Uniated Nations Population Fund. (2018). World population trends. Uniated Nations Population Fund. https://www.unfpa.org/world-population-trends

Wittman, H. (2011). Food Sovereignty: A New Rights Framework for Food and Nature? Environment and Society, 2(1), 87-105. https://doi.org/10.3167/ares.2011.020106

\section{Bibliografía consultada}

FAO. (2020d). Indicador 2.5.1.a - Número de recursos genéticos vegetales para la alimentación y la agricultura preservados en instalaciones de conservación a medio y largo plazo. FAO - Food and Agriculture Organization of The United Nations. http://www.fao.org/sustainable-development-goals/indicators/251a/es/ 